\title{
Systems fail, technology disappoints, and relying on optimism is not enough: A short analysis of teacher wellbeing and digital learning solutions
}

\author{
ISSN 2657-9774; https://doi.org/10.36534/erlj.2021.02.06 \\ Ervin Kovačević \\ International University of Sarajevo, Bosnia and Herzegovina \\ ekovacevic@ius.edu.ba
}

\begin{abstract}
This is a call for support that teachers, students, and a large number of education systems need in order to prevent teacher attrition, improve learning experiences, and invest in the future of schooling. The call is based on a brief review of recent studies and reports, which reveal teachers' dissatisfaction with their working conditions, the negative results generated by online teaching solutions during COVID-19, and the limitations which characterize our education systems. The conclusions recommend taking immediate actions which would improve teacher wellbeing and job satisfaction, lead to the massive preparations that digital teaching solutions require, and offer quality schooling opportunities to all schoolchildren worldwide. The humility of this call lies in the recognition that it cannot achieve much on its own. However, by arguing that decreasing in trends in the levels of motivation among both students and teachers be evaluated as outgrowths of systematic flaws in education rather than of the characteristics of individual students and teachers, the paper encourages broader engagement with the potential to lead to meaningful reform.
\end{abstract}

Keywords: education systems, online education, teacher attrition, wellbeing, COVID-19

\section{Introduction}

I was eleven years old when the last war broke out in Bosnia and Herzegovina. At that time, I was a fifth-grader in the small but moderately developed city of Tuzla, located in the northeastern region of my country. Having evaluated the risks of living in a city that was periodically bombed by heavy artillery, my parents moved my sister and me to the village where my grandparents lived, twenty-five kilometers away from Tuzla. This meant that I had to finish the fifth grade in a new school. Although it was challenging, I managed to fit in. At the beginning of my sixth-grade year, many of the teachers I had just met left the school. Their substitutes had varying and, in many cases, limited levels of training and experience, but it seemed that my and my peers' education was not at risk. I graduated with honors.

When I began attending a high school in Istanbul together with other Bosnian peers from different cities and scholastic backgrounds, I did not struggle at first. For example, I learned English and Turkish fairly quickly. However, at some point, I began to struggle with some of my science courses-particularly with Physics and Chemistry, the two courses in which I had almost no foundational knowledge. The school had a demanding schedule with intense testing, and unlike some of my schoolmates, I never excelled in those two subjects. By my junior year, I had lost my enthusiasm for natural sciences and decided that I would stick to the disciplines with which I was most comfortable, such as foreign languages, history, and geography.

I sometimes wonder whether proper training in primary school science courses would have made a difference in my later academic success and professional orientation. Today, as a teacher trainer, I find myself deeply concerned by the potentially negative impact that the COVID-19 pandemic will have on early, primary, secondary, and higher education. Prior to COVID-19, the education system in Bosnia and 
Herzegovina had not been fully restored to its pre-war quality. The Program for International Student Assessment (PISA) ranked my country sixty-fourth out of seventy-eight countries on average scores in mathematics, science, and reading in 2018 (Facts Maps: 2018). The highest-ranking country, China, scored 578.7 points, while the lowest-ranking country, the Dominican Republic, scored 334.3 points. Bosnia and Herzegovina scored 402.3 points. Between the lingering social consequences of war and numerous economic challenges, the road ahead is strewn with obstacles. What is more, the arrival of COVID-19 has delayed our academic renaissance even further.

If this renaissance is to happen at any point in the near or distant future, it cannot be achieved so long as we rely solely on teachers' enthusiasm and conscientiousness, which they are expected to maintain on their own and in spite of myriad challenges. Their personal and emotional wellbeing, working conditions, and professional development need to be continuously and effectively facilitated. This article presents a review of some alarming trends regarding teachers' dissatisfaction with their jobs and suggests that the leading authors in all fields of education start pointing more vigorously to the challenges that teachers face on a regular basis. The article also highlights a few findings, which show that our current digital technology cannot substitute authentic and context-dependent personal teaching methodologies, and that the research on digital teaching solutions has a long way to go.

\section{Systems fail}

The flaws plaguing school systems can be understood in the rates and reasons of teacher attrition, going back to before the advent of COVID-19. For example, a recent report on the U.S. teacher labor market (García \& Weiss 2019: 1-5) reveals the following:

1. The percentage of public-school teachers who either leave their schools or completely quit teaching is 13.8 .

2. A large share of schools struggle to fill vacancies. For instance, in $2016,9.4 \%$ of schools could not fill a vacancy, and $36.2 \%$ of schools found it very challenging.

3. Certified and experienced teachers leave prematurely, and the percentage of newly hired, inexperienced teachers is increasing.

4. It was estimated that the schools needed 110,000 new teachers in the 2017-2018 school year.

5. From 2008 to 2016, the number of students enrolled in teacher programs dropped by $37.8 \%$, and the number of graduates from such programs dropped by $27.4 \%$.

García and Weiss (2019: 1) note that high-poverty schools are under more pressure to retain and hire teachers, and that they identify "low pay, a challenging school environment, and weak professional development support and recognition" as the main factors that need to be addressed. A more recent article (Joseph 2021) illuminates some of the reasons teachers quit teaching based on the personal accounts of former teachers. The following examples reveal that teachers' tolerance for low pay, heavy workloads, and poor working conditions has its breaking point:

My sister was a teacher; during the pandemic they asked her to double up and teach both English and math. For the upcoming fall, they said "teach English, math, science, and history or you can return to teaching music like you were hired for half pay." She promptly quit :(A tweet by @ LordFenrir)

Quit teaching English, got a job in recruiting making 20k more per year (was making master's degree salary as a teacher), now I can WFH, and I bank a lot of time off due to schedule flex. Also was paid for my 4 months of maternity leave. And no more admin to judge my pedagogy. (A tweet by @TheLWWay85)

A quarter of the teachers in my school left after this draining year, and many of us who are left are strategizing our way out. I love my students and want to do everything possible for them, but I'm just so tired. Teaching takes years off lives. (A tweet by @Maty0707). 
The article (Joseph 2021) ends by emphasizing the overall lack of support for teachers, remarking that a profession characterized by a lack of support and limited professional development opportunities cannot be attractive to young students.

These trends are not unique to the U.S. For example, the Netherlands is another developed country, which struggles with teacher attrition (den Brok et al. 2017). Although the rates of teachers leaving the profession in the Netherlands are lower than in U.S., den Brok et al. (2017: 887) find that their reasons for leaving are quite similar. Their review of available reports shows that $12 \%$ of primary and $13 \%$ of secondary school teachers leave the profession within five years. The review also shows that between 12 and $32 \%$ of education-program graduates never enter the teaching profession. The number of working hours, working tempo, emotional exhaustion, negative student behavior, lack of feedback and support, unclear institutional expectations, low salary, and personal problems were some of the reasons why teachers quit.

Thirty-five European countries have recently reported a shortage of teachers (Eurydice Report 2021). Eight of those countries have also reported an oversupply of teachers in some fields, which can be explained by varying and inadequate planning of initial teacher education and teacher recruitment rates. The shortage is evident in subjects such as the sciences, mathematics, and foreign languages (Eurydice Report 2021: 30). Nineteen European countries also have problems attracting students to teacher education programs as well as preventing students from dropping out of these programs (Eurydice Report 2021: 34).

Pljevljak (2021) researched the wellbeing and experiences of primary and secondary school English teachers in Sarajevo Canton (Bosnia and Herzegovina) during COVID-19. Sixty-two teachers were surveyed. Thirty-eight of them taught in primary schools, and twenty-four taught in secondary schools. Seven had more than twenty years of teaching experience, twenty-nine had between ten and twenty years of teaching experience, fourteen had between five and ten years of teaching experience, and twelve of the teacher respondents were in their first five years of teaching. The study gives valuable insight into the respondents' personal experiences and perceptions of the profession, including the following:

1. When the teacher respondents were asked whether they see themselves doing their job until their retirement, $23 \%$ did not and $18 \%$ were not sure.

2. Only $28 \%$ of the respondents agreed that their job gave them purpose in life and enabled personal empowerment during the pandemic.

3. The majority (67\%) agreed that the amount of administrative work increased during the pandemic, and $46 \%$ identified parents as an additional source of stress.

4. The majority (74\%) agreed that lesson planning was more time consuming and found testing and getting reliable results difficult (71\%) during the pandemic.

5. Only $18 \%$ agreed that the relevant ministry provided timely and adequate guidelines to make English language teaching easier.

These findings show that the current state of the teaching profession in some of our education systems is far from perfect. It is disappointing to note that despite the calls to improve the teaching profession, which date back to 1987 (e.g. Burke at al. who reported that $50 \%$ of U.S. teachers leave the profession after seven years), not much has changed. Teachers, as the foundational elements of our education systems, are underappreciated; their contributions to world cultures are undercompensated, and their profession is less popular than ever. It could be argued that this is not always the case. Finland, a country that has been known for the quality of its education system, encourages teachers' autonomy, non-standardized testing, and taking care of their health and wellbeing (McGowan 2018). However, it needs to be noted that very developed countries where job opportunities are abundant allow for career changes, which is not true for countries with very high rates of unemployment. In these places 
therefore, a teacher may remain in the teaching profession for the sake of maintaining a regular paycheck rather than because she or he is happy with the profession. Overall, it seems that education systems fail their teachers, and thus both their own and world cultures. In order to reverse these trends, teachers should receive more attention (not control), support (including, but by no means limited to the financial) and better working opportunities (with which teachers can be motivated).

\section{Technology disappoints}

Modern technologies have their benefits but also their drawbacks. For example, utilizing fossil fuels makes our lives easier, but it also negatively affects global warming. In a similar fashion, the advantages of contemporary educational technology are numerous, but there are also some limitations. Learning tasks are easily enhanced, rich learning resources can instantly be made available, word prediction and translation software can assist in various activities, lessons can be recorded, and both teaching and learning can be done from the coziness of your home (Soffar 2019) -that is, of course, if your home is cozy. A report (UNICEF COVID-19 2020) shows that $58 \%$ of countries did not provide a digital solution for pre-primary education, $26 \%$ of countries did not do it for primary education, and $23 \%$ did not do it for upper secondary education. The report estimates that $49 \%$ of students from pre-primary to upper secondary levels were not engaged in Eastern and Southern Africa while 9\% were neglected in Latin America and the Caribbean. Overall, it concludes that 463 million schoolchildren worldwide were not engaged in this transition.

Until September 2021, COVID-19 had prevented 1.8 trillion hours of traditional in-class meetings and made 131 million of students miss approximately $75 \%$ of their in-person schooling (UNICEF Education Disrupted 2021). To substitute for the lack of in-person contact, almost all countries adopted remote schooling channels, which primarily utilized either the internet or TV/radio broadcasting. However, 31\% of schoolchildren around the world could not be reached through these methods (UNICEF COVID-19: 2020). The most commonly employed means were online platforms; however, these were only accessible to roughly one quarter of children worldwide. Only $25 \%$ of schoolchildren who live in rural areas and poor households had access to remote methods (UNICEF Education and COVID-19: 2020). It should be noted that these statistics only show the percentages of children who did and did not have access to remote learning during the pandemic. Even if a significant number were reached by these methods, it does not mean that the instructional processes were effective. Pre-COVID-19 PISA results show that although class meetings do provide opportunities for formative assessment, immediate feedback, and equal opportunities, not all class meetings produce the same results. The effects of discrepancies generated by COVID-19 are yet to be analyzed. One can reasonably estimate, however, that the impact of these discrepancies will not be positive.

Digital education solutions have also been utilized in Kosovo, Albania, Nigeria, and Bosnia and Herzegovina. The following review of four studies which have addressed some of their national online learning solutions during COVID-19 show that education systems-including its policy makers, researchers, designers, and implementers-have many issues to tackle before we can fully embrace online education solutions.

Beka (2021) explores online teaching experiences with one hundred and two teachers and ten principals working for sixty-eight primary and secondary schools in Kosovo. The following findings are worth noting:

1. The majority of teacher respondents (54.9\%) reported having felt stressed before their online lessons.

2. Three of four teachers agreed that one of the biggest challenges was their inability to supervise their students' participation and learning behaviors. More than a half of respondents $(54.9 \%)$ were concerned with whether their students were focused on the lesson content. 
3. The majority (60.8\%) was constantly concerned about whether their students understood what was taught.

4. The principals reported being aware that not all of their students had the necessary electronic devices and internet access.

5. The principals described the relevant ministry as too slow in providing guidelines and regulations about online learning and suggested reversing the decision-making mechanism; the initial school-based initiatives worked, and there is significant evidence that their autonomy should be enhanced.

Beka (2021) concludes that the switch to online teaching solutions brought teachers, parents, and other relevant institutions together and proved that education systems can be transformed. It should be recognized that this conclusion refers to the shared willingness to provide educational services during COVID-19 lockdowns; to what extent the researched education system has indeed been transformed is too early to estimate.

Taraj (2021: 82) investigates "synchronous e-learning during the second semester of the 2019-2020 academic year" with a survey administered to one hundred and sixty-eight undergraduate students in Albania. The following findings are highlighted in the report:

1. The majority of respondents (54.8\%) used smartphones to join their online sessions, $42.8 \%$ used computers, and $2.4 \%$ stated not having any digital device.

2. One hundred and ten respondents think that they could benefit from additional training about online learning.

3. Approximately one quarter of respondents liked new educational technology and enjoyed selfpaced learning.

4. Approximately $40 \%$ of respondents identified lack of motivation, poor internet connection, and lack of immediate feedback as disadvantages of online learning.

5. Three of four respondents found face-to-face interaction with teachers and peers easier than virtual interaction.

6. Only $16.1 \%$ of student respondents agreed that they would like to have online courses in the future.

7. The majority (60.7\%) preferred face-to-face learning.

Taraj (2021: 92) attributes some of the negative experiences with online learning to poor internet connection, lack of digital devices, and levels of computer literacy. The author argues that the government needs to address the first two factors and believes that the issues of computer literacy can be addressed through modifications in mandatory curricula. One of the recommendations for college instructors is to "respond to the students more frequently by giving instant feedback which can increase their intrinsic motivation and participation in the e-classes" (Taraj 2021: 92). It can be argued that the recommendation would be more easily embraced if it was accompanied with the recommendation that the instructors' teaching workloads get decreased.

Aduba and Mayowa-Adebara (2021) surveyed one hundred and eighty-seven sophomore undergraduate students and interviewed three lecturers at Delta State University in Nigeria about their experiences with online platforms. Some of the reported findings are as follows:

1. A large majority of student respondents $(94.6 \%)$ found that online learning is eye straining.

2. The majority of student respondents $(52.4 \%)$ reported not having a smartphone.

3. Three quarters of student respondents reported network problems.

4. Almost half agreed that they lack skills necessary for using online learning applications.

5. The interviewed lecturers identified "cost of paying for data, network failure, laxity of students, ... [being] unable to conduct exams, and nonchalant attitude of students toward lectures" as barriers in delivering online lessons (Aduba \& Mayowa-Adebara 2021: 12). 
The researchers recommend that the university management provide its instructors with Wi-Fi, support alternative ways for conducting exams, and encourage utilizing different online platforms for different educational purposes (Aduba \& Mayowa-Adebara 2021: 12).

Lagumdžija and Eminović-Ljevo (2021) explore to what extent online solutions integrate traditional teaching techniques. Some of the findings based on the interviews with four English as a Foreign Language (EFL) instructors working for the International University of Sarajevo (Bosnia and Herzegovina) can be summarized as follows:

1. Pair and group work is not usually conducted in online meetings.

2. Some EFL instructors speak more during online meetings than they do during traditional classroom meetings. One of the reasons is their not being sure whether students are present and engaged.

3. Students seem to prefer in-person instruction, find online lessons less important, and miss socializing with their peers.

The researchers conclude that the interviewed instructors were aware of occasional shifting towards more traditional solutions. However, they explained the shift by technical difficulties and students' lack of motivation.

It is not uncommon for online learning solutions to rely on traditional material delivery techniques such as lectures (whether pre-recorded or synchronous), short or long topic presenting texts, and follow-up multiple choice comprehension tests. For example, QEDEX, an online learning platform designed to deliver "the quality of teaching and learning in all education sectors across the world" (QEDEX) heavily relies on such techniques. It should be noted that significant efforts, which can be traced back to the first half of twentieth century, have been cultivated so that learners could benefit from cognitivist, constructivist, social constructivist, or experientialist (not to mention recently embraced neuronalist) teaching agendas which rest on moving away from treating learners and their minds as containers that need to be filled with information (cf. Kovačević 2021: 5-45). It is truly disappointing that some contemporary online education practices are nullifying the major (but unfortunately inconclusive) progress in general education theory.

It should be emphasized that experiences with online/remote education during the COVID-19 pandemic depend on national standards. The Online Education Trends Report (Venable, 2021), which is based on a survey answered by 1,800 students and 366 school administrators in the U.S., lists positive findings such as the following:

1. Three quarters of student respondents found online learning better than or at least as good as on-campus learning.

2. Half of the remote learner respondents expect to enroll in online courses after educational processes mainly return to campus sites.

3. Half of the administrators believe that more investment in instructional design solutions is not necessary.

Different and more pessimistic findings are presented in a report on online and remote education experiences in Afghanistan, Brazil, Cambodia, Estonia, Haiti, Malawi, Mozambique, Niger, Nigeria, Nepal, Pakistan, Peru, Rwanda, Sierra Leone, and Uruguay (Barron Rodriguez et al. 2020):

1. Multimodal delivery systems were more effective in urban than in rural areas. This is true for each of the five modes: paper-based, mobile learning, online platforms, TV, and radio.

2. Only Estonia and Uruguay, the two highest-income countries included in the study, relied on hightech solutions alone.

3. Low and middle income countries do not have the infrastructure and internet connectivity necessary to make use of online education solutions. For example, only 40,000 schools in Brazil, out of 141,000, are connected to the internet; although all of the 270,000 schools in the Edo-BEST 
system in Nigeria had some experience with advanced technology-based teaching solutions before COVID-19, their remote learning program reached only $29 \%$ of their student population during the pandemic.

These contrasted findings highlight the disparities that characterize education systems across the globe. While our local educational truths may be more or less encouraging, somewhere in the world a student, teacher, parent, or school administrator is faced with different realities, which can be much better or much worse than our own. Having the best of intentions to offer viable global solutions, researchers and authors sometimes produce solutions, which are more valid for their immediate environments than other educational contexts. Therefore, as we explore digital teaching solutions, we must remember that some of us are deprived of basic communication technologies.

\section{Relying on optimism is not enough}

Moving towards an uncertain future for worldwide education should be rooted in optimism. The existing systems can and must be improved. The findings reviewed so far in this paper show that significant numbers of teachers and students appear to be dissatisfied with the ways in which schools are run and education is being delivered. Just giving up or acquiescing to negative trends should definitely not be seen as an option. Yet, for those interested in improving any education system, simply criticizing or suggesting reforms for current teaching practices yields few results. This is because in order to achieve meaningful and lasting results, there are several foundational stones, which must be laid, or re-laid, as the case may be. These stones include quality working conditions and environments, teaching contracts, wages and pace of wage progression, the amount of public appreciation for teachers' work, and teaching workload demands (cf. Eurydice Report 2021: 141).

Data obtained by the 2018 Teaching and Learning International Survey (Eurydice Report 2021: 143), which was answered by 260000 teachers and 15000 school leaders, reveals the following as the top five sources of teachers' work-related stress:

1. Having too much administrative work to do (53.2\%)

2. Having too much grading $(48.6 \%)$

3. Being held responsible for students' achievement (47.3\%)

4. Keeping up with changing requirements from authorities (45.6\%)

5. Maintaining classroom discipline (41.7\%).

The data analysis reveals that well-behaved classes, higher levels of teacher collaboration, and higher levels of teacher autonomy are associated with lower levels of stress for teachers (Eurydice Report 2021: 147). However, these three factors are only related to the working climate and culture. Factors such as working time, experience, contract type, and perceptions of self-efficacy are also worth considering as they may elevate or ease work-related stress and increase or decrease job satisfaction (see Eurydice Report 2021: 148).

By denying teachers adequate wages, favorable contracts, and working conditions conducive to their well-being, we deprive our children of their educators' full potential. In doing so, we impede the growth of our societies, cultures, economies, and overall quality of life. We need to dismiss the myth that teachers are idealistically driven martyrs, who do not require the same level of comfort in life afforded by other professions. Like anyone else, teachers deserve to be able to lead lives of comfort, security, and enjoyment, with the assurance that they will also be able to live out their senior years in dignity after retirement. Two out of five teachers in the EU are not satisfied with their salaries, and one out of five are on a temporary contract (Eurydice Report 2021). The dissatisfaction is higher in countries with lower GDP per capita. In other words, the countries, which need to increase the overall quality of lifestyles, have less satisfied teachers. Our profession cannot systematically attract the brightest minds so long as education offers less to its employees than other industries. Governments around the world must invest 
more in quality education systems if they expect future generations to be both willing and able to give back to their societies.

Teacher training programs need to regain some of their lost appeal. This is only possible if the teaching profession is more effectively valued and associated with an attractive and comfortable lifestyle. Unfortunately, attempts to do so, such as annually rewarding best teachers, have the potential to mislead. While rewarding those with the most outstanding achievements may sound reasonable, it sends the message that the onus of excellence falls on individual teachers, in the circumstances where serious government intervention is needed to address underlying obstacles. For example, the altruistic and extraordinary deeds of Peter Tabichi, the Kenyan Math and Physics teacher who won the Global Teacher Prize in 2019, can inspire all teachers to do more for their students. Yet Peter's challenges actually speak about Kenya, and what it does and does not do for its people, students, and teachers. While teaching heroes like Peter or Andria Zafirakou, the recipient of 2018 Global Teacher Prize, can of course be a focal point for education interest and research, this should not distract from the focus on teaching systems and the agents who run them, which must be intensified. A top-down approach based on informed decision making, field data, and strategic investment can be an alternative starting point. The studies reviewed in this article (García \& Weiss 2019, den Brok et al. 2017, Eurydice Report 2021, Pljevljak 2021) demonstrate widespread dissatisfaction among teachers with their working conditions. Government and non-governmental actors with the ability to influence schooling systems can start there.

Significant investments are especially needed in the transition to digital schooling. If there are any global efforts to abandon traditional schooling frameworks and replace them with computerassisted/online learning solutions, every education stakeholder will need some time before they start dwelling and excelling in the new reality. Many parts of the world have weak economies, underdeveloped internet infrastructure, schoolchildren living in poverty, undertrained instructors, and poor digital teaching solutions. While COVID-19 introduced almost all of us to some remote teaching alternatives, the experience has been partly disappointing for many teachers, students, and parents, with questionable outcomes for society at large. Many lessons have been learned, many platforms have been mastered, new solutions have been proposed; but the general consensus remains that the oldfashioned classroom environment has hard-to-beat advantages.

If digital teaching solutions have partly failed the COVID-19 test, there are several reasons. One recent analysis identifies an inclusive approach to digital solutions, curricula planning, teacher training and development policies, sustained monitoring and evaluation policies, and national strategies as factors that have potential to elevate our digital teaching performances (cf. Barron Rodriguez et al., 2020). While the analysis derives from large-scale research that has included experts from at least fifteen countries, the conclusions sound familiar: education systems require more attention and investment. This can come from governments, non-governmental bodies, philanthropists, or any conscientious individual who is willing to actively join forces to provide every student with an effective learning environment. We need to stop pretending that mediocre solutions are sufficient to address the dire obstacles to education, which are hindering learning outcomes worldwide. We cannot continue to allow economic disparities to dictate the educational outcomes of our children, leading us towards a dystopian future where children from prosperous areas thrive, while children from underdeveloped areas must accept limited visions of their potential. Different parts of the world and specific scholastic contexts have different challenges to address in order to maximize the effectiveness of their school systems. The studies reviewed in the previous section (Beka 2021, Taraj 2021, Aduba \& MayowaAdebara 2021, Lagumdžija \& Eminović-Ljevo 2021, Venable 2021, Barron Rodriguez et al. 2020) reveal that experiences with online education vary. All of them report various challenges that need to be addressed, such as internet infrastructure, lack of electronic devices, underexplored potentials of digital 
education, the power of social and interactive contact, or a lack of collective awareness about pitfalls of digital education. Alongside obstacles, many also report positive experiences.

\section{Conclusion}

It may be argued that this call to action is too modest and lacks the potential to reach the policy makers who are empowered to set new courses in education history. However, it can reach other researchers and authors who may use alternative channels to disseminate some of the facts about contemporary education. These are the facts that speak of larger flaws in our education systems such as the following:

1. Interest in teaching careers is declining.

2. The weaker interest in teaching careers can be explained by public appraisal and self-perception of the teaching career.

3. Stronger economies provide better working conditions for their teachers. However, this is not always true.

4. Education systems across the world significantly differ in their capacities to modernize their practices and benefit from digital solutions.

5. Covid-19 has emphasized the disparities not only between different countries but also between urban and rural areas serviced by one education system.

This article has proposed that all education stakeholders take immediate action. These actions will vary according to the particularities of education systems and their growth capacities. The recommendations are based on the review of very recent studies and the author's humble understanding of ongoing education practices and their potential to foster the progress of human civilization. It is recognized that further research is necessary to validate some of the presented recommendations. The task of validation may require longitudinal studies which are not easy to conduct, but whose findings could inform new policies in education. If we wait for another pandemic to make serious changes to our educational systems, these will no doubt once again be rooted in a naive optimism that things will turn out for the best, rather than any critical evaluation of the current systems' impediments and shortcoming. We must reflect on the lessons that the present period has taught us, continue to collect data, and enhance our readiness to enact digital education solutions.

\section{References}

Aduba, D. E., Mayowa-Adebara, O. (2021). Online platforms used for teaching and learning during the COVID-19 era: The case of LIS students in Delta State University, Abraka. International Information \& Library Review, 1-36. https://doi.org/10.1080/10572317.2020.1869903.

Barron Rodriguez, M., Cobo, C., Muñoz-Najar, A., Sánchez Ciarrusta, I. (2021). Remote learning during the global school lockdown: multi-country lessons. Washington, D.C.: World Bank Group.

Beka, A. (2021). Transformative school initiatives through the use of digital technologies in Kosovo during Covid-19. Ilkogretim Online - Elementary Education Online, 20(1), 851-860. http://ilkogretimonline.org.

Burke, P. J., Christensen, J. C., Fessler, R., McDonnel, J. H., Price, J. R. (1987). The teacher career cycle: Model development and research report. Annual meeting of the American educational research association. Washington.

den Brok, P., Wubbels, T., van Tartwijk, J. (2017). Exploring beginning teachers' attrition in the Netherlands. Teachers and Teaching, 23(8), 881-895, https://doi.org/10.1080/13540602.2017.1360859.

Eurydice Report (2021). Teachers in Europe: Careers, Development and Well-being. Eurydice report. Luxembourg: Publications Office of the European Union. 
Facts Maps (2018). PISA 2018 Worldwide Ranking - average score of mathematics, science and reading. FactsMaps.com. https://factsmaps.com/pisa-2018-worldwide-ranking-average-score-of-mathematicsscience-reading/. Accessed on 22 December 2021.

García, E., Weiss, E. (2019). The teacher shortage is real, large and growing, and worse than we thought: The first report in 'The Perfect Storm in the Teacher Labor Market' series. Economic Policy Institute. https://www.epi.org/publication/the-teacher-shortage-is-real-large-and-growing-and-worse-than-wethought-the-first-report-in-the-perfect-storm-in-the-teacher-labor-market-series/. Accessed on 3 December 2021.

Joseph, J. (2021). Former teachers reveal what made them quit and it explains why there are teacher shortages. Good \& Upworthy. https://scoop.upworthy.com/former-teachers-reveal-why-quit-explainsteacher-shortages? Accessed on 21 December 2021.

Kovačević, E. (2021). Teaching Adult English Language Learners: Enhancing Personal Methodologies. International University of Sarajevo.

Lagumdžija, E., Eminović-Ljevo, A. (2021). Is COVID-19 forcing ESL instructors to return to more traditional teaching in the second language acquisition methodology? Educational Role of Language Journal, 1(5), 18-29. https://doi.org/10.36534/erlj.2021.01.02

McGowan, M. (2018). 'Too much control': Pasi Sahlberg on what Finland can teach Australian schools. The Guardian. https://www.theguardian.com/australia-news/2018/jan/07/pasi-sahlberg-finlandteach-australian-schools-education Accessed on 21 December 2021.

Pljevljak, S. (2021). Canton Sarajevo primary and secondary schoolteacher wellbeing and experience during the COVID-19 pandemic [Master's Thesis International University of Sarajevo].

QEDEX. The Global Community for Higher Education Professionals to Continue Lifelong Learning. https://www.qedex.org/. Accessed on 23 December, 2021.

Soffar, H. (2019). Pros and cons of technology in education \& Can technology replace teachers? https://www.online-sciences.com/technology/pros-and-cons-of-technology-in-education-cantechnology-replace-teacher. Accessed on 23 December 2021.

Taraj, G. (2021). What do college learners think of synchronous learning? International Journal of Learning, Teaching and Educational Research, 20(4), 82-98. https://doi.org/10.26803/ijlter.20.4.5

UNICEF COVID-19 (2020). COVID-19: Are children able to continue learning during school closures?: A global analysis of the potential reach of remote learning policies. https://data.unicef.org/resources/remote-learning-reachability-factsheet/. Accessed on 21 December 2021.

UNICEF Education and COVID-19. (2020). Education and COVID-19. https://data.unicef.org/topic/education/covid-19/. Accessed on 21 December 2021.

UNICEF Education Disrupted. (2021). Education disrupted: The second year of the COVID-19 pandemic and school closures. https://data.unicef.org/resources/education-disrupted/. Accessed on 21 December 2021.

Venable, M. A. (2021). Online education trends report. Best Colleges.

https://www.bestcolleges.com/research/annual-trends-in-online-education/. Accessed on 8 February 2022. 